\title{
GLOBAL CLIMATE CHANGE MITIGATION AND SUSTAINABLE FOREST MANAGEMENT - THE CHALLENGE OF MONITORING AND VERIFICATION
}

\author{
WILLY R. MAKUNDI \\ Lawrence Berkeley National Laboratory \\ University of California, Berkeley, USA
}

\begin{abstract}
In this paper, sustainable forcst management is discussed within the historical and theoretical framework of the sustainable development debate. The various criteria and indicators for sustainable forest management put forth by different institutions are critically explored. Specific types of climate change mitigation policies/projects in the forest sector are identified and examined in the light of the general criteria for sustainable forest management. Areas of compatibility and contradiction between the climate mitigation objectives and the minimum criteria for sustainable forest management are identified and discussed. Emphasis is put on the problems of monitoring and verifying carbon bencfits associated with such projects given their impacts on pre-cxisting policy objectives on sustainable forest management. The implications of such policy interactions on assignment of carbon credits from forest projects under Joint Implementation/Activities Implemented Jointly initiatives are discussed. The paper concludes that a comprchensive monitoring and verification regime must include an impact assessment on the criteria covered under other agrecments such as the Biodiversity and/or Desertification Conventions. The actual carbon credit assigned to a specific project should at least take into account the negative impacts on the criteria for sustainable forest management. The value of the impacts and/or the procedure to cvaluate them need to be established by interested partics such as the Councils of the respective Conventions.
\end{abstract}

Key words: sustainable forest management, climate mitigation, criteria and indicators, carbon offset projects

\section{Introduction}

The forest sector plays a significant role in the accumulation of greenhouse gases (GHG) in the earth's atmosphere, and has a potential to play an even bigger role through GHG emission reduction and/or increasing carbon dioxide $\left(\mathrm{CO}_{2}\right)$ sequestration in vegetation, detritus, soils, and biomass-based products. In the IPCC Climate Change Report (1995a), it is estimated that if various measures are implemented in the forestry sector, it is possible to sequester between 1.2 and 1.8 billion tonnes of carbon $(\mathrm{Pg} \mathrm{C})$ annually for the next 50 years.

Despite the high profile accorded to forests in the climate change debate, the state of global forests and their rate of depletion had been of concern in the international community for some time. The impact of humans on the world forests has led to a decline of about a third of the original expanse estimated at 6.2 billion hectares (Lanly, 1982). The problem is more critical in the tropical regions, where an estimated 154 million hectares were lost in the decade ending 1990 alone (FAO, 1993a). As such there have been numerous efforts at national and international levels which emphasize the need to manage forest resources sustainably, with the tropical forests receiving much of the attention.

Some of the most notable initiatives include the Tropical Forestry Action Plan (TFAP) (WRI, 1987), the International Tropical Timber Agreement (ITTA, 1984) which sought to achieve a sustainable use of tropical forests, as well as the 
Noordwijk Declaration (Noordwijk Report, 1989), which called for a net increase of global forest cover by 12 million hectares annually. More recently, linked to the United Nations Conference on Environment and Development (UNCED, 1992) the "Forest Principles" issued under Agenda 21 urge the global community to pursue sustainable management and conservation of all types of forests.

The twin objectives of using forestry to mitigate climate change and managing forests sustainably do pose a challenge in monitoring and verifying benefits from carbon offset projects in the sector. The purpose of this paper is to explore the concept and practice of sustainable forest management and its compatibility with global climate change mitigation. The likely impacts of various types of mitigation policies on a minimum set of criteria for sustainable forest management are identified and discussed. Issues associated with assigning credits from such carbon-offset policies/projects and the implications on a credible monitoring and verification regime are high-lighted.

\section{Background}

Forests have always been a primary resource in human sustenance and development. They have been the main source of agricultural and pasture land, wood fuel, solid wood, fibre, environmental services, and a host of valuable non-timber products. The dependence on forests for these and other goods and services has led to depletion of large portions of the global forests, with tropical forests being the most vulnerable due to high growth rate of land-dependent population and fast increase in the demand for tropical forest products. The severity of the problem varies across regions, but it is most critical in Asia and central and south America.

In southeast Asia, only a third of the land area is currently covered with forests (D'Silva and Apannah, 1993) and it is estimated that the rate of deforestation in India, Nepal, Philippines, Sri Lanka, Thailand, Malaysia, and Indonesia is approaching 2 million hectares per year. At this rate, the original forest cover in the region, which exceeded 725 million hectares, will be halved by the turn of the century. Furthermore, in a region which is home to about half the world's population, it is estimated that agriculture needs an additional 20-25 million ha by year 2000 . This trend seems to be incongruent with the goals to increase the land area currently under forests, for example: (a) India to $30 \%$ from $23 \%$ (b) China to $20 \%$ from $13 \%$ (c) Thailand to $40 \%$ from $28 \%$ (Makundi et al., 1992).

The fast growth of many economies has been driving the excessive demand for tropical forest products. About 5.5 million hectares of undisturbed tropical forests are logged every year, and another 7.5 million hectares of logged-over forests are annually re-logged (Lanly, 1982; Myers, 1984). The disappearance of forests is linked to their economic value under the existing modes of utilization. Logging is responsible for the deforestation of about 1.5 million hectares annually (FHB, 1994), which is about 10 percent of the world's deforestation. Timber is the second foreign currency earner after oil, earning $\$ 4.2$ billion for Indonesia in 1991 , and $\$ 3.8$ for Malaysia in 1992. To make matters worse, the Asian region, 
which has the fastest growing economies in the world, is rapidly becoming wooddeficit and the World Bank (1992) projects that by the year 2000, the region will import forest products to the tune of $\$ 20$ billion a year. For example, India has seen its import bill for industrial roundwood expand from $\$ 1.8$ million in 1981 to $\$ 124$ million in 1991 . Such trends are at the root of the various efforts intended to manage forest resources sustainably.

Associated with the deforestation and consumption of forest products are emissions of GHG to the atmosphere. The world's forests store large quantities of carbon, estimated at $340 \mathrm{Pg} \mathrm{C}$ in vegetation and $620 \mathrm{Pg} \mathrm{C}$ in soils. Changes in land use in lower latitudes are estimated to contribute between 1.1 to $2.1 \mathrm{Pg} \mathrm{C}$ of net emissions annually into the atmosphere (IPCC, 1995b), mostly from south and central America and Asia. This trend is projected to worsen to varying degrees in each region. For example, in the absence of effective mitigation policies, the Asian forests, which are currently responsible for about $6 \%$ of the rise in atmospheric $\mathrm{CO}_{2}$, are projected to contribute much more because they are uniquely close to centers of rapid economic and population growth, and so they are more vulnerable than comparable expanse of forests in other regions (World Bank, 1992). The deforestation of the Amazon continues to dominate emissions from land-use changes (Feamside, 1996).

However, forests can also play a major role in absorbing atmospheric carbon. There is a large capacity for forest ecosystems to sequester carbon by increasing biomass density in existing forest lands through natural and enhanced regeneration, as well as expanding carbon stocks by conversion of non-forest lands to forests. The mid- and high-latitude forests are estimated to be a net sink of between 0.5 and $0.9 \mathrm{Pg} \mathrm{C}$ annually (Brown et al., 1996). Although there is some controversy over biomass equilibrium in mature forests, a few recent studies seem to suggest that some apparently mature tropical forests sequester up to $2 \mathrm{tC}$ per hectare annually (Grace et al., 1995; Lugo and Brown, 1992).

Measures to reduce emissions from land-use changes, as well as a combination of carbon sequestration in existing forests and in new forests, offer a real opportunity to reduce the amount of $\mathrm{CO}_{2}$ in the atmosphere, most of which comes from burning fossil fuels. The United Nations Framework Convention on Climate Change (UNFCCC) as indicated in paragraph 1 (d) of Article 4 of the Convention commits signatories to:

promote sustainable management and cooperate in the conservation and enhancement of sinks and reservoirs of all greenhouse gases not controlled by the Montreal Protocol, including biomass, forests and oceans as well as other terrestrial, coastal and marine ecosystems (United Nations, 1992).

Other sections of the UNFCCC specifically require systematic observation of pertinent areas related to the climate system, including inventory of GHG and the impact of response strategies.

Pursuant to the commitment to manage forest resources sustainably, the United Nations Council for Sustainable Development (UNCSD) established the Inter-governmental Panel on Forests (IPF) in 1995, with a mandate to formulate relevant policies for meeting the challenges of sustainable forest management. Other related instruments resulting from the UNCED process that have a direct

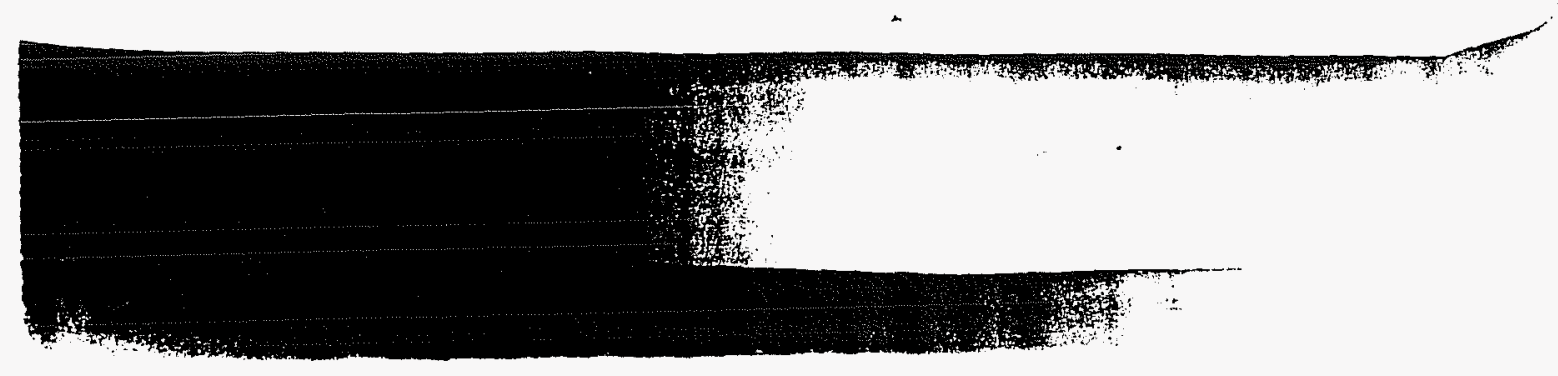


bearing on the management of global forests include the Convention on Biological Diversity and Convention to Combat Desertification. These policy instruments must be taken into account when addressing the role of forests in the global climate system.

Reconciling the two objectives of managing forest resources for climatechange mitigation and achieving sustainable forest management pose some interesting challenges arising from the ambiguous definition(s) and the existence of diverse multiple objectives for sustainable management of forests within the context of sustainable development.

\subsection{DEFINITIONS OF SUSTAINABILITY}

The verb sustain originates from the Latin word sustenere, meaning to maintain at an elevated position. In practice, the concept of sustainability alludes to an unending state, be it of a static entity or of a dynamic process such as the use of resources. In its theoretical form, sustainability involves a perpetual time frame, but in practice the time horizon implied is that period within which the level of the static or dynamic "state" is desired. Whereas sustainable supply of oxygen refers to infinite time horizon, the sustainable supply of coal may only refer to a few decades needed to phase out the use of such an energy source.

In the conventional resource-utilization context, the idea has often been used to refer to a physical concept of either a single resource or of an intertwined group of resources such as an ecosystem. The emergence of a more comprehensive school of thought, which approaches sustainability as a socio-economic concept associated with the management and use of physical resources (Dixon and Falcon, 1989), has broadened the debate and made the practical application of the concept much more complex.

Sustainable development was defined in the World Commission on Environment and Development Report, commonly known as "The Brundtland Commission," using very general but compelling language. The term was defined as:

development that meets the needs of the present without compromising the ability of future generations to meet their needs (WEC, 1987).

In order to translate this general definition to specific applicable policies, a myriad of definitions have sprouted everywhere (Michael, 1992), serving different interest groups, at times with diametrically opposed objectives (O'Riordan, 1988). Different countries have tried to formulate relevant policies of varying degrees of sophistication to achieve sustainable development. One of the more comprehensive coverage of the term is contained in Costa Rica's Sustainable Development Strategy (Quesada, 1990), where sustainability is defined as:

...a dynamic process in which management of natural resources, the empowerment of human beings, the focus of scientific and technological development, the formulation of new legal and administrative schemes, and the orientation of the economy fortify the options to satisfy the basic necessities of the current generation 
without destroying the ecological base or the life support systems on which future development and environmental quality depend.

The concept of sustainable development is historically related to sustainability of a natural resource in use. In resource management such as forestry, fishing, and wildlife, the concept is commonly referred to as sustained yield, which has been used to imply "a harvesting regime for a reproducible natural resource that could be maintained over time." In forestry, the concept has its formal roots from the 19th century German forester Faustmann (Gane, 1968) who advanced a framework for determining the economic rent for land used for perpetual forest management.

In ecology the concept of sustainability is used more broadly, and in general carries the meaning of "preserving the status and function of entire ecological systems." On the other hand, in economics, the concept is used with emphasis on the "maintenance and improvement of human living standards." in which natural resources and the environment are only a part of the story. In other fields such as geography and anthropology, the term is used with emphasis on "maintaining social and cultural systems" such as the preservation of indigenous peoples' knowledge (O'Riordan, 1988, op.cit.)

To effectively be translated to natural resource management, the concept of sustainability must be construed to include the preservation and maintenance of a reproducible resource or the capacity to produce the goods and/or services obtainable from it by current and future generations. This would tend to include the GHG emission reduction role of the forest. However, the additional sequestration role does not automatically derive from the conventional sustainability concept, but is here treated so since climate mitigation is one of the contemporary roles of global forests. To discern the ecosystem's ability and potential to provide these functions, one needs to know the initial state of the resource, which tends to lead to different sustainable stream of outputs, each requiring different set and amounts of inputs to achieve. Such initial states may include: (i) equilibrium forest ecosystems - mature forest, (ii) growing forest, e.g., secondary forest or a young plantation or (iii) non-forested land, e.g., grasslands, exhausted and abandoned agricultural land, and other land uses convertible to forestry.

Under an equilibrium forest ecosystem, sustainability alludes to conservation of the ecosystem, such that it maintains its ecosystem functions. Such measures may include protection against natural disturbances such as catastrophic crown forest fires or epidemics, which may significantly alter the ecosystem. However, since most ecosystems are degraded by human activities such as conversion to agriculture, pasture and harvesting, the most effective measures to conserve such areas should be those geared towards eliminating human encroachment, including rural development policies, harvesting and marketing of non-timber forest products, land tenure, tax disincentives, gazetting, and surveillance of protected areas .

Sustainability of an ecosystem, which initially constitutes a growing forest such as a plantation or secondary forest, must be consistent with the desired future use of the forest area. If the area needs to be reverted to an equilibrium ecosystem, then the case becomes the same as that discussed above. If the area is slotted for 
production forestry, then sustainability of this ecosystem implies the ability of the forest to recover from disturbance(s) and produce the desired goods and services repeatedly. Measures to make this possible may include active management of the area, enhanced regeneration, and even altering the species composition through partial or complete introduction of other desired species. A monocultural forest plantation constitutes an extreme form of this regime and will be referred to as sustained yield management as described below.

The third type of initial state involves non-forested land such as grasslands and abandoned pastures or agricultural lands. Sustainability of such areas must also be consistent with the desired transitional and final states. In some cases, the land needs to be left as open grassland or rangeland to play its necessary role. In other cases, these areas are amenable to conversion to other land uses through afforestation, natural or enhanced regeneration, eventually turning to a desired ecosystem like production forest, catchment area, soil stabilization forest, etc. It is obvious that sustainable forest management can only be defined within the parameters of the initial state of the ecosystem, as well as the desired transitional and final state of the area. Managing forests to meet specific or general human needs has been practiced to a degree for some time.

In the context of this paper, we will use a definition of sustainable forestry as that management regime which produces forest products and services at a level compatible with the maintenance of the ecological processes that sustain the forests (Johnson and Carbale, 1993). Although this is applied more frequently to natural forest management, the idea is just as valid for human-grown or modified forests. The sustainability aspect covered here does not address the "deep ecology" point of view, which tends to discount the superiority of human needs over other species.

This definition of sustainable forest management is still deficient since it mainly focuses on streamlining the supply of goods and services from the resource, without paying any attention to the demand structure which dictates the levels of consumption. Taking the demand and prices as exogenous to the management regime will force the examination of sustainability to be mainly concentrated on physical flows of goods and services from the forest, and pay little attention to the social and economic factors surrounding the use of forest resources.

\subsection{SUSTAINED YIELD IN FORESTRY}

The apparent change in paradigm between conventional sustained yield and that of forest conservation and sustainable development is now finding more and more coverage in the literature (Damodaran, 1992; D'Silva and Appanah, 1993 op. cit.; FAO, 1993b; Aplet, 1993; Maser, 1994). As mentioned earlier, sustained yield management has been used in forestry to imply the production of steady and perpetual flow of timber. The extreme idealization of this is what is referred to as a "normal forest", which constitutes a forest with an age structure which allows for production of equal annual volume of wood in perpetuity (Brasnett, 1953).

Although the concept of sustained yield was initially conceived for even-aged 
forests (Gane, 1968 op. cit.), various technical approaches have been tried to apparently achieve what has often been referred to as sustainable forestry in natural forests. Such practices typically involve some silvicultural operations such as liberation of desirable species by cutting climbers and opening canopy, as well as transplanting desirable species (often commercial timber spp.) to increase their density, and light pruning to enhance vertical growth and merchantibility of desired species. The regime has also discouraged clear-cutting and emphasized less destructive harvesting methods commonly known as selective harvesting e.g., patch and strip-felling, shelterwood selection system, single tree extraction, etc. Although there are relatively few natural forests managed this way (Poore et al., 1989), there is no good evidence that this regime constitutes sustainable management, even for timber production (WRI, 1991).

It is argued that the system has not been in use long enough in diverse enough ecosystems to allow a comprehensive evaluation of its performance under the stated objectives. Furthermore, some evidence exists to show that selective harvesting has been associated with substantial damage to non-target vegetation (Johnson and Carbale, op. cit.). The manipulation of species structure tends to favor those species which are more valuable under current utilization technologies and consumer preferences, thus reducing the sustainability of the other timber species which have potential uses given technological and market changes. It would therefore seem that sustained yield forestry is but a subset of sustainable forest management which focuses on timber production, while the latter covers a wider array of goods and services.

\subsection{NATURAL FOREST MANAGEMENT}

Although the concept of sustainable forest management has its roots in sustained yield forestry, it involves a broader scope and more complex spectrum of goods and services. However, the case for sustainable management of natural forests has mostly been based on showing that the economically useful species regenerate naturally after initial harvesting, and in a few cases, after the second rotation (Keto et al., 1990; Poore et al., op. cit.). The case against this claim is based on the fact that natural regeneration covers only a few species and it has not been shown that the pre-harvesting species and biomass density is ever achieved in successive rotations (Moad, 1989). This historical caveat not withstanding, most policies on sustainable management of natural forests seem to imply a desire for restoration of the ecosystem to its pre-utilization condition, involving regeneration of the original species mix, restoration of soil conditions and reconstitution of the ecological functions of the area (Freezailah, 1994). However, a deeper examination of this widely held view on sustainability of natural forests reveals a more complex reality.

For a production forest, a complete re-constitution of the prior ecosystem may not be feasible, neither desirable - given the management objectives. Once the forest is sufficiently disturbed, some of the macro and micro ecosystems are altered in very profound ways, unleashing a mosaic of dynamic processes at species and substrate level. Such changes may include the edaphic and microbial conditions, hydrological and temperature regimes, extent and duration of exposure 
to light, structure of the residual vegetation, and a different regenerative mixture of seeds, seedlings, saplings, and coppices. These conditions dictate the dynamic processes which will eventually lead to a new equilibrium. Under an irrevocably degraded ecosystem, possibly from unsustainable forest resource utilization, the new eco-equilibrium is significantly different from the pre-utilization equilibrium.

There are other important transitional-state issues which need to be addressed when dealing with ecosystems which have been disturbed by human activity or natural causes. Even if the utilization was conducted in such a way that it would ensure a re-constitution of the original ecosystem, such a process takes a long period of time. Different utilization regimes lead to different recovery paths each with different time horizons, and none with a 100 percent chance of total reconstitution. Each path has a different probability of recovery, depending on inter alia, the initial conditions, the disturbance intensity, the likelihood of seeding (e.g., from surrounding vegetation), and most important of all, the nature of intervening events after the disturbance, whether natural or anthropogenic.

It is also important to note that the disturbed ecosystem was not a static system, but rather a dynamic mosaic of biota, substrate and ambiance. Although the forest may be seen as a stable equilibrium, there are processes and micro ecosystems which are constantly changing. Indeed, the whole forest may actually be in a particular stage of change, except that most of the natural and normal change is quite slow, thus giving an impression of an equilibrium at the macroecosystem level. It is not obvious that the entire ecosystem can ever be reconstituted, neither is it obvious that this is necessary for sustainability to be realized. Strict interpretation of re-constitution would require one to predict the ecosystem structure and function at the future date, upon which the recovering forest area can be evaluated and compared. This is a difficult task that can be approximated through comparison with undisturbed ecosystems of same/similar structure prior to the disturbance.

On the other hand, one has to acknowledge that the ecosystem function is a continuum which has various utility to humans at different time periods. Timber may be the product which is harvested 30 years after the initial disturbance, but other annual and shorter-term products may actually be available prior to full recovery. Water catchment capacity is one such service, as well as herbs and fruits. There exists other transitional functions which would not otherwise have been obtained under the initial equilibrium. A good example is the fact that the pioneer vegetation after harvesting (especially clear cutting) precedes a climax vegetation and some of the functions of the pioneer ecosystem are different from the climax ecosystem. Herbs, fruits, pollen, and habitat provided during the transition is a different set of goods and services, some of which can not be provided by mature climax vegetation.

Transitional goods and services from recovering deforested areas which meet Brundtland Commission definition of sustainable development with regard to satisfaction of inter-generational needs, tend to lend credence to the more liberal definition of sustainable forest management. Such a view must consider recovering natural forest as an integral part of a natural forest sustainable management system, which provides various goods and services as secondary forests compared to climax forests. If transitional forest products and services are 
included in the examination of sustainable forest management, the issues of monitoring and verification must then include measuring the production adequacy during these transitional states, and not only the production capacity of the equilibrium states.

To the extent that forestry policies or projects are intended to mitigate climate change - such as those falling under JI/AIJ iniatives, their impact on sustainable natural forest management should be assessed in light of the issues of reconstitution, transition, and equilibrium states of the ecosystem. Monitoring equilibrium-state goods and services can be undertaken using standard biometrical and productivity tracking methods. Surveys and biomass studies are the most common methods to estimate timber output and other products. Transitional products and services such as fruits and hydrological control, can be monitored periodically as they come on stream. These products and services will vary from one project to another, and over the lifetime of the project, and as such, accounting for them should be based on established methods for measuring the ecosystem's yield at various times. However, the climate mitigation benefits should be evaluated against some clearly defined criteria for sustainable forest management, paying specific attention on the impacts of such projects/policies on the criteria.

\section{Criteria for Sustainable Forest Management (SFM)}

In policy analysis, a criterion is defined as a distinguishing characteristic of an instrument that provides policy framework, while an indicator refers to a measurable variable in relation to a criterion (Maini, 1993). More specifically, FAO (1995) defined a criteria in this context as "identified elements of sustainability against which forest management can be assessed." Ecologists have identified a set of minimum ecosystem health indicators which should be used to monitor the state of a forest which has been disturbed in comparison with the preceding virgin ecosystem (Johnson and Carbale, op. cit.).

\subsection{ECOSYSTEM HEALTH INDICATORS}

Assessment of the following list of indicators provides a good basis for evaluating the health of a given ecosystem, which in turn forms one of the tenants of determining whether an ecosystem is being managed sustainably given the social objectives.

(i) Biodiversity

The status of fauna and flora at various intervals, especially those responsible for seed dispersal and pollination of plants on-site and off-site is important for biodiversity assessment. A healthy ecosystem with biologically diverse populations should have the capacity for natural regeneration of important pioneer and climax species and to accommodate a natural balance of animal, insect, and bird populations. In its broader definition, biodiversity does subsume most of the other ecosystem health indicators since it includes landscape patterns, habitat and guild structure, taxic composition, 
hydrological characteristics, etc. However, for the purpose of assessing SFM criteria, these indicators need to be addressed separately.

(ii) Nutrient status

Availability of mineral and organic nutrients, including the rate of depletion or accumulation provide information about the capacity of the ecosystem to support vegetation.

(iii) Microbial and soil fauna

Density and activity levels of soil modifying microbes and micro/macro fauna.

(iv) Hydrological characteristics

Thawing, water quality, flow, retention, and evapo-transpiration rates.

(v) Edaphic and landscape stability

Soil erosion and translocation of litter and organic matter to other areas, including downstream water bodies.

(vi) Microclimate

Soil temperature, moisture, and humidity govern germination and seedling/sapling survival.

(vii) Natural disturbances

Propensity of fires, epidemics, wind impact should be monitored over time.

Unsustainable forest management has adverse impacts on each one of these indicators. Although the indicators tell us the health of the ecosystem, sustainable forest management is not always defined or interpreted from this point of view. Various institutions such as the International Tropical Timber Organization (ITTO) and the United Nation's Food and Agricultural Organization (FAO) have attempted to identify the essential elements of a sustainable forest management policy. Since 1990, but more so after UNCED summit in Rio, there have been a number of efforts to identify the relevant criteria and indicators for sustainable forest management. The conclusions of each of these initiatives reflect the forces driving the effort, although some common elements appear in each set of criteria and indicators. The three levels of interest, that is global, national and management-unit, necessitate identification of criteria which address each level's concerns.

The ITTO, responding to timber market pressures, came up with five national criteria with 27 associated indicators and six site-level criteria with 23 indicators. The most important criteria are summarized in Section 3.2. In 1994, the European Union through the Helsinki process arrived at a combination of six criteria and 27 indicators for sustainable forest management, while a non-European group concerned with temperate and boreal forests under the so called Santiago Declaration in 1995 identified six criteria and 67 indicators (ISCI, 1996). Both the Helsinki and Santiago initiatives were responding to pressures from environmental groups concerned with respective forest ecosystem management. On the tropical front, the eight countries which are signatories of the Amazonian Cooperation Treaty advanced the Tarapoto proposal, listing 12 criteria with 77 indicators, with the emphasis being on the sustainable utilization of the Amazon 
resources for their national socio-economic development, while paying some attention to environmental concerns. The last major effort was a proposal with seven criteria and 47 indicators for Dry-Zones in Africa which was spearheaded by the UN as an outgrowth of the UNCED process. Since our main interest lies in the compatibility of sustainable forest management with climate mitigation policies and/or projects, we will use the ITTO and FAO criteria to highlight the areas of compatibility and contradiction which must be addressed in the course of monitoring and verification of such projects/policies.

\subsection{ITTO'S CRITERIA FOR SFM}

One of the first institutions to put forth criteria upon which sustainable forest management should be based was the ITTO. Article $1(\mathrm{H})$ of the International Tropical Timber Agreement (ITTA, 1983), the legal instrument which instituted ITTO, clearly states that the objective of the organization is "to encourage the development of national policies aimed at sustainable utilization and conservation of tropical forests and their genetic resources, and at maintaining the ecological balance in the regions concerned" (ITTA, 1983, 1994). Pursuant to a 1988 survey (Poore et al., 1989) of sustainable management in tropical timber producing countries which found that only a negligible amount (less than 1 million hectares) of the world's moist tropical forests were managed sustainably, and consistent with the agreement's preamble and article $1(\mathrm{H})$, the ITTO issued a working definition of sustainable forest management in 1990. This definition emphasizes production of a continuous flow of desired forest products and services without undue reduction of the forest's inherent values and future productivity, and without undue undesirable effects on the social environment (ITTO, 1992). In an attempt to translate this principle into a policy framework, the organization issued a list of 41 guidelines intended to move countries towards the goal of sustainable forest management (ITTO, 1990).The following criteria constitute the key elements addressed by the guidelines:

(i) Establishing a permanent forest estate. A need to establish a permanent forest estate (PFE), whether public or private, in order to secure optimal contribution of forests to national development. The main categories to be set aside include land for nature conservation, protection forestry, timber production, and other forest products, or a combination of these objectives. The guidelines recommended that in establishing the PFE, the area should be surveyed and clearly demarcated in consultation with surrounding populations, taking into account their present and future needs for agricultural land and their customary use of the forest.

(ii) Conservative harvesting levels. A need to set conservative harvesting levels (annual allowable cut) bearing in mind current limited understanding of tropical forest dynamics. In practice, this will mean conservative setting of rotation age, felling cycles, girth limits, and selection intensity, parameters which will be amended as permanent sample plots begin to yield more reliable information about the forest dynamics. Environmental impact assessment should be carried out prior to harvesting, and logging damage to residual vegetation minimized. 
(iii) Involvement of local people. In recognition of the importance of social issues, the guidelines state that the success of forest management for sustained timber production depends to a degree on its compatibility with the interests of local populations, and they should be consulted prior to planning and implementing forestry operations.

(iv) Strong political commitment. A need for a strong political commitment to a national forest policy on sustainability, supported by legislation and in harmony with other sectors. The interests of all players should be considered, with the concessionaires ensured of long-term viable concessions. Benefits of local population must be taken into consideration while management and governments receive sufficient revenues from the operations, since forest management for timber production can only be sustained in the long term if it is economically viable.

The ITTO hopes that if such criteria are adhered to, the tropical timberproducing countries will move closer to a more sustainable forest management, with a strong emphasis on timber production, without blatant disregard for the other products and services from the forest estate. There is still some skepticism on the effectiveness of this policy because the criteria are seen as too narrow with the timber production aspect dominating the other aspects (Goodland, et al., 1990).

A recent study by Rice and Gullison (McRae, 1997) on the effect of applying the ITTO criteria to the Chimanes Permanent Timber Production Forest in the Bolivian Amazon indicates that this criteria tends to lead to a serious loss of biodiversity, mainly due to the silvicultural requirements for regeneration of the targeted timber species; in this case the shade intolerance for mahogany. Under certain circumstances such as the remoteness of the forest, prevailing interest rates, enforcement regimes, etc., even the commercial timber trees for which these criteria of sustainability is focused get severely depleted. Such concerns have made the development of a more comprehensive set of criteria for sustainable forest management very imperative. In response to this need, the UN FAO (1995) proposed a short list of basic objectives which would form the foundation for a sustainable forest management policy.

\subsection{FAO'S CRITERIA FOR SFM}

The FAO's criteria incorporate most of the ecosystem health indicators, but also address some of the key services of tropical forests, including climate change. The following is the summary of the criteria and the corresponding indicators:

(i) Protection of biodiversity. This will involve setting aside areas deemed necessary for biodiversity and protecting from encroachment those already conserved for this purpose.

(ii) Maintenance of forest productivity, which will ensure a sustained flow of forest products for human consumption, from both natural and human-grown forests.

(iii) Maintenance of forest vitality to ensure and/or increase the capacity of the forest to support life. Also maintain and improve the resilience of the 
ecosystem.

(iv) Protection of soil and water, specifically for reducing soil erosion and improving water catchment role of the forest. Soil protection will also reduce emissions of soil carbon and enhance soil carbon storage.

(v) Contribution in carbon cycling. Under this item, emphasis should be on:

- utilizing biomass to substitute fossil fuels e.g. biomass-based power plants to replace fossil fuel electricity generation,

- sustainable harvesting of timber from natural forests.

- plantation timber substituting for emission intensive materials such as steel, cement and plastics in construction, industrial packaging and in furniture,

- plantation timber production to substitute for natural forest timber,

(vi) Enhancing social and economic benefits through:

- sustainable harvest of timber and non-timber products

- matching demand and supply of forest products and services (both short and long term)

- by generating incomes, employment, taxes, foreign exchange, and improvement of rural infrastructure.

The theme of this criteria for sustainable forest management is to run the forest estate for provision of goods and services while maintaining the integrity of the ecosystem. However, some of the objectives may prove to be contradictory when applied in small ecological units. For example, economically viable timber harvesting may not be reconcilable with maximization of biological diversity on the same forest tract. It is unlikely that timber harvesting can be reconciled with biodiversity of rare insects, epiphytes, microbial organisms, or avi fauna. Another objective which contradicts some of the sustainability criteria is reduction of net carbon emissions. While the objective for contribution to carbon cycling deals with climate change issues directly, each of the other objectives have an indirect impact on GHG emissions and/or carbon sequestration in the forest sector. In the next section, we examine the relevance of sustainability criteria from the various foci to climate change mitigation.

\section{Sustainable forest management and climate change mitigation}

As mentioned earlier, sustainable forestry has often been explored using the physical resource approach, where sustainability consists of managing the forest resource without reducing the stock, which in turn is determined by site factors such as nutrient availability, climate, precipitation, species composition, etc. If the ecosystem is in equilibrium in terms of biomass, any harvesting involves drawing down the stock, albeit temporarily. Biomass harvesting for sustainable forest management involves the removal of biomass not exceeding the periodic growth (usually mean annual increment). For this to be consistent with the broader definition of sustainable development, such harvesting has to observe the 
SFM criteria as well as fall within the legitimate human needs. Since it is difficult to determine the appropriate level which is required by society, the minimum one could do is to utilize as much of the biomass extracted as possible and assume that in the absence of major distortions in the economy, prices will arbitrate the optimal level of consumption.

Different practices in forest management may be construed to be sustainable, and yet they have distinctively different implications on biodiversity as well as carbon cycling. The classical examples often quoted are those involving the conversion of natural forests to rubber plantations (e.g., Malaysia, Thailand, Indonesia, etc.), versus latex tapping from rubber trees in natural forests (e.g., Brazil, Bolivia, etc.). The former constitutes an economically sustainable regime, although it has a very low biodiversity index, while the latter is economically unsustainable (due to competition from rubber plantations) but is environmentally sustainable with a high biodiversity index. The two options have very different GHG implications. Determining the criteria which carries more weight is at the core of the problems of reconciling the SFM objectives to those of climate mitigation.

In this section, we attempt to link the issues associated with climate change mitigation in forestry to the specific standing policies under sustainable forest management. The problem is first examined at general policy level to see how sector-wide mitigation policies interact with sustainability criteria. Then we discuss the likely impact of specific types of mitigation projects on the SFM criteria.

\subsection{SECTOR-WIDE MITIGATION POLICIES}

At general level, mitigation policies must address the areas where significant reduction of emissions and/or carbon sequestration are possible. The most effective mitigation policies should reduce emissions through reduction of deforestation. Sustainability at the forest management unit level must take place within a conducive framework of sustainable management of the forest sector, preferably as a part of a sustainable development policy. An area of priority would be to formulate policies which address the core causes of tropical deforestation.

By and large, tropical forests are lost through clearing for farming and pasture, extraction of woodfuel and fodder, and excessive commercial logging. In general, the process is driven by socio-economic policies governing land use, development strategies, trade, and other macro-economic policies. However, at the sector level, the three major failures which underlie the tropical deforestation crisis include those related to economic policy in forestry, institutional inadequacies, and lack of technological improvements.

In the policy area, there has been a divergence between private and social costs, that is, those who derive private benefits from the public forests do not compensate society the full costs associated with their actions which is borne by others. The symptoms of these failures include setting stumpage prices lower than the cost of replacing the removed trees under various guises such as supporting forest-based industrialization in the country by using cheap local inputs.

The institutions which are in place were established decades ago, in most 
cases during colonial era, with structures which served the mandates of the time, mainly to administer harvesting of timber resources for the metropolis, and protect the forests from "encroachment" by local communities. For historical reasons, these institutions lack community support, and they operate in an environment with ambiguous property rights. As such, they can not adequately serve the contemporary purposes of social forestry and multiple-use management for local and global environmental services.

The technical factors contributing to deforestation include lack of adequate information on the dynamics of the ecosystem, e.g., species structure, growth rates, interdependence of members of the ecosystem, poor understanding of impacts of various harvesting schemes, use of old vintage technologies for converting timber to products, etc.

Changes at the level of forest policy, institutions, and technological improvements which reduce deforestation are most likely going to be consistent with the SFM criteria. However, in the short term, there may be some dislocations as may happen in the case of laid-off workers who were dependent on a logging company which was operating unsustainably. The intertwined nature of the economy and the critical position of forestry as a primary sector makes it difficult to monitor and verify the impacts of sector-wide mitigation measures.

Modifications in stumpage-pricing policy, increases in concession fees, or establishment of decentralized and more responsive institutions, and increased research efforts can be monitored and their implementation be verified at various times. The impact of such policies cannot be easily assigned to each individual aspect, but a change in the trend of deforestation should be considered as an indicator of their effectiveness. However, due to intersectoral effects and linkages between policies, the verification regime should carefully include assessment of new or other policies in the sector and related sectors which reverse and/or contravene the intent of the mitigation policies. Monitoring the deforestation trend by itself is not adequate to evaluate the impact of these general level measures.

\subsection{IMPACT OF MITIGATION PROJECTS}

Climate change mitigation projects in forestry involve three types of actions. The most effective in the short term are the GHG emission-reduction measures such as forest conservation and efficiency improvement in biomass extraction and utilization. The second type involves sequestering carbon in existing and expanded ecosystems such as in reforestation, afforestation, and agroforestry. The last projects are those intended to substitute non-renewable carbon-intensive products such as fossil fuels, chemicals, construction material, and unsustainably harvested wood with sustainably grown biomass and its derivatives. Each one of these mitigation policies is related to sustainable forest management in some form. To examine the interaction of these two major objectives, we will use the FAO criteria which seem to offer potentially good stewardship of forests and possibly a good chance for sustainable forest management.

In the criteria listed under Section 3.3, carbon cycling is explicitly mentioned as an objective of SFM. However, each one of the sustainable forest management 
objectives is collaterally related to climate change via GHG emission reduction or by carbon sequestration. Also, the feedback effects from climatic change such as $\mathrm{CO}_{2}$ fertilization, succession and migration of ecosystems, etc. will impact each one of the SFM criteria (Solomon and Cramer, 1993). It should be borne in mind that any assessment of the interaction between carbon offset projects and SFM criteria is complicated by the uncertainty in the dynamics of natural forests and the long production periods involved. In natural forest management, cause and effect can not easily be predicted (Maser, 1994).

Assessing the performance of a management regime given a set of criteria may pose some difficulties due to lack of comparable indicators (Prabhu, 1994). Criteria such as preservation of biodiversity or degree of social acceptance may not be easily measured and trade-offs between criteria are even more difficult. The complex dynamics of forestry make any action or policy implemented in the sector have multiple inter-related effects, many of them being incidental to the main objective of the policy. In this section we will attempt to discuss the collateral impacts of mitigation projects on sustainable forest management.

In previous sections we alluded to the various types of indicators and criteria which have been put forth by different sources. To illustrate the pertinent issues of SFM and climate mitigation in forestry, we have listed the FAO criteria in Table 1 against the various types of mitigation projects in forestry. We try to score in each case the likelihood of impact of a typical project in each category on the SFM criteria, showing whether the criteria will be affected positively (enhanced), negatively (harmed), or whether the project has no impact (neutral). The usefulness of such information is to indicate how each project will influence SFM criteria. The mitigation criteria, i.e., emission reduction or carbon sequestration, should be considered in light of the impact the project has on other standing commitments towards sustainable forest stewardship.

The country in which the project is to be implemented may already be committed to the SFM criteria in prior international agreements such as the biodiversity convention. SFM may be vital to existing national aspirations as indicated by plans on resource management. To the extent that the effect of a given project is non-neutral, the monitoring and verification regime must include thorough assessment of the impacts on SFM criteria over and above the emission reduction or C-uptake goals of the project. The impacts that enhance other standing criteria may not be as contentious as those which negatively affect the criteria. In any case, the inclusion of such impacts in cost-effectiveness indicators of a given mitigation project will depend on the evaluation of the collateral impacts. The final value may require some level of bargaining between interested parties, for example, between the Secretariats for CBD and FCCC or their functionaries.

\subsubsection{Protection and conservation projects}

As shown in Table 1, there are a variety of possible mitigation projects which are likely going to reduce emissions through protection of the ecosystem. Such projects may be undertaken specifically for climate mitigation purpose, or for conservation objective, with carbon as a collateral effect. Each project type will be 


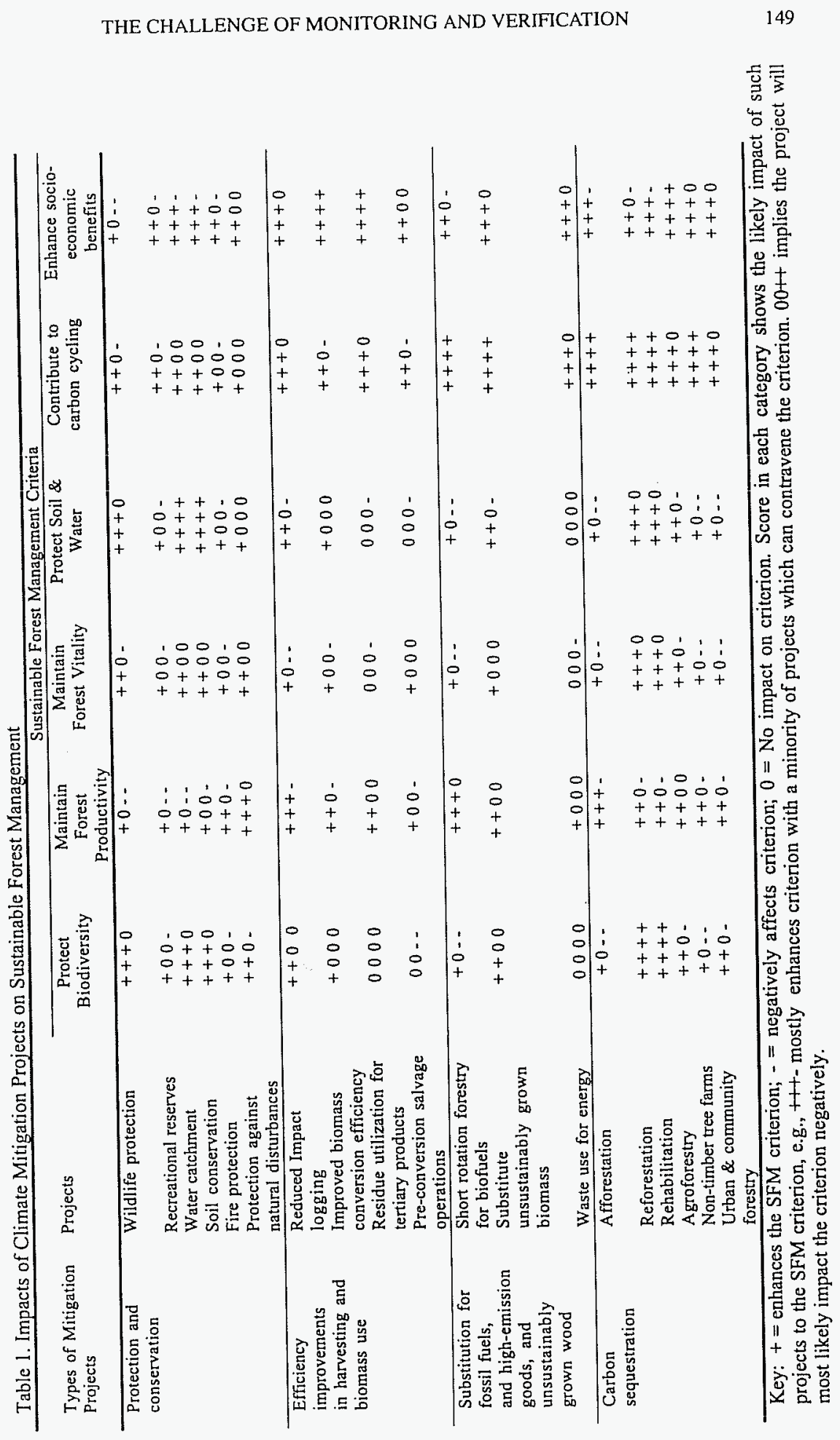


examined assuming that its primary objective is climate change mitigation.

Projects for wildlife protection (flora and fauna) are more likely going to enhance carbon cycling. Those which are intended for forest protection willconserve carbon, and if the ecosystem was not in biomass equilibrium, there is an opportunity to sequester carbon. If the project is geared toward protection of wild animals, the contribution to carbon cycling will depend on the wildlife management regime. In the extreme, the project may loose carbon if the animal population grows to exceed the carrying capacity of the reserve. Evidence of habitat destruction by elephants has been shown in some wildlife reserves in east and southern Africa.

Protection and conservation tends to enhance biodiversity as well as protecting soil and water, with a slight chance of neutral impact on these two attributes depending on the initial state of the ecosystem. Such a project is likely going to reduce the flow of products such as timber, which may have been procured prior from the reserved area, and consequently they may reduce direct socio-economic benefits. However, since the area will be preserved, there is a possibility of producing other types of benefits such as ecotourism, scientific knowledge, and possibly micro-climate modifications which may enhance other socio-economic benefits.

The impacts of recreational reserves are similar to those of forest and wildlife reserves, except that they have a bigger chance of having a negative impact on biodiversity if over-used by visitors. Also, the negative impact on socio-economic benefits is reduced since recreational activities tend to generate more income and has a general positive impact to the society.

Water catchment reserves and soil conservation projects have either a neutral impact or most likely enhance carbon cycling. They are more likely to enhance biodiversity and maintain forest vitality on top of protecting soil and water. These projects will tend to enhance the socio-economic criteria by stabilizing water flow, providing irrigation and household water down stream while reducing erosion and siltation. There may be a reduction in benefits associated with products which were previously obtained from the catchment area.

The impacts of fire protection projects on the various criteria are quite uncertain. If the area has been subject to regular human-caused fires, such a project will reduce emissions from oxidized woody biomass, as well as reducing emissions of methane, nitrous oxides, and oxides of nitrogen in the short-term. However, the extent of these reductions will depend on the type of fire protection, with prescribed burning leading to the least reduction in non- $\mathrm{CO}_{2}$ emissions. In the longer term, the fuel loading resulting from averted fires may lead to major crown fires which will lead to more emissions than prior to the project. The impact on the other criteria follows a similar trend, except that the project may enhance socio-economic benefits by reducing the frequent destruction of biomass.

Strictly speaking, protection against natural disturbances such as windfalls, natural fires, and botanical epidemics, should not be considered a mitigation measure, but it can be so interpreted if one considers that resulting emissions are anthropogenic by way of omission of preventive action. Given the nature of disturbance, such action is likely going to reduce carbon emission and enhance each of the other criteria or leave them neutral. The only negative impact could be 
on biodiversity, where the pests are eradicated, or where the dead wood would have served as a substrate for many new lower forms of life in the ecosystem.

So, in conclusion, the GHG benefits from conservation and protection projects are most likely going to be positive, and in many cases they enhance the other criteria on SFM. However, there are possibilities of some negative impacts on carbon cycling but more so on the other criteria. These impacts need to be evaluated together with the GHG benefits so as to provide a basis for weighing the trade-offs.

\subsubsection{Efficiency improvements}

Any increase in the amount of usable biomass extracted and/or reduction in collateral damage during harvesting reduces associated carbon emissions. Projects like reduced impact logging enhance carbon cycling criteria by reducing the vegetation which is turned to necromass during logging (Pinard and Putz, 1997). This harvesting method will more than likely improve the social economic benefits by reducing the destructive effects of conventional logging. Applying reduced impact logging will enhance biodiversity or leave it unchanged, although there is a chance of reducing biodiversity compared to un-logged forest. Forest productivity is also improved since the method reduces the damage on the remaining ecosystem, and the directional felling and better skid management reduces the deleterious effect on soil. Since any harvesting reduces crown cover and opens up patches for water runoff, the impact on water catchment can be negative depending on the harvesting method practiced before. Although the technique attempts to maintain the integrity of the ecosystem, the capacity of the forest to support life may not be increased by this method.

To increase the biomass conversion efficiency and the use of biomass residues for producing tertiary products will reduce the emissions from waste and reduces the forest area which needs to be harvested to meet a given level of product demand. Increasing recovery of timber, charcoal, or firewood reduces carbon emissions and clearly would seem to enhance socio-economic benefits. There is a slight possibility of a project of this nature leading to increased emissions by making the use of unsustainably produced biomass more economically attractive and as such delay the consumers' movement to cleaner fuels. These types of projects have little or no impact on biodiversity or water and soil protection, except perhaps enhancing it by reducing pressure on new forest land.

Pre-conversion salvage operations increase the use of the biomass from a forest area instead of leaving it on-site for decomposition. To the extent that the biomass is used for products, then the socio-economic benefits are enhanced, and mostly no impact on soil and water protection. However, if most of the biomass is removed, the area may be exposed to erosion and also depleted of organic matter-derived nutrients, thus reducing its productivity. Depending on the fauna and flora of the area, such operations will most likely lead to a reduction of biodiversity.

\subsubsection{Substitution}

Using sustainably produced biomass to substitute for fossil fuels either by 
producing biofuels, producing power or direct burning unambiguously reduces emissions. The same thing applies when we use sustainable procured biomassbased products e.g. wood instead of cement for construction, or chemicals. Utilizing wood waste for energy generation also reduces emissions from decomposition and may reduce emissions from "dirty fuels" used for producing energy.

Short rotation forestry may reduce biodiversity if it replaces a rich natural ecosystem, but it could be neutral or even enhance the criteria if it is practiced in a farmland or degraded land. Replacing unsustainably produced wood with sustainably-grown biomass will most likely enhance biodiversity, whereas waste use for energy has little or no impact on biodiversity. Forest productivity and socio-economic benefits are enhanced by the substitution projects, although forest vitality and protection of soil and water may be diminished by short rotation forestry for biofuels with waste utilization for energy having no impact at all.

\subsubsection{Carbon sequestration}

Carbon sequestration projects seem to have the most direct positive impact on carbon cycling, with agroforestry and community forestry having a slight chance of neutral effect depending on the farming practices and possible emissions from soil disturbance. Reforestation and rehabilitation clearly enhance biodiversity and afforestation and non-timber tree farms may contribute negatively simply because they are usually monocultures or at most consist of a few species.

Afforestation increases forest production most, but the other types of projects also enhance productivity or have little impact. Depending on the type of vegetation replaced by non-timber tree farms, urban community forests, and afforestation, there is a likelihood to reduce forest productivity, especially if the area's prior use was multiple-use forestry. Reforestation and rehabilitation projects largely enhance forest vitality and protection of water and soil, while the projects with few species are likely to reduce both soil and water protection and forest vitality. By and large, all the sequestration type of projects enhance socioeconomic benefits by producing forest goods and services in areas which were being used for other purposes.

\section{Discussion and conclusion}

Sustainable management of forests does not necessarily imply constant or smooth flow of goods and services. The interaction between a dynamic ecological and socio-economic system is likely going to lead to fluctuating flows. The main concern of a sustainable system is to ensure that there is no major sustained imbalance between demand and supply for the goods and services, given the constraints imposed on the system such as maintenance of biodiversity, protection of soil and water, etc.

Monitoring all indicators for each project requires technical expertise as well as financial resources. The cost per unit of climate mitigation indicator, e.g., tonnes of sequestered carbon, will be increased by the cost of monitoring and verifying the 
state of, and changes in the other indicators for sustainable forestry.

There are three types of indicators, management unit (on-site), national, and global. The relevant indicators will vary between projects and countries. It is essential to identify core indicators for each project, consistent with national criteria and indicators, and possibly with some regional correspondence. For a JV/AIJ project, these core indicators will be a part of the negotiation between the host country and the investor. In some cases, wherever a global criteria is core to the project, e.g., biodiversity, but disregarded or lightly weighted by the host and/or investor, a global arbitrator may need to be involved in the trade-off negotiations. Such players whose interest may need to be balanced with the interest on the FCCC include The Biodiversity Council, Intergovernmental Panel on Forests, Desertification Convention, etc.

The assignment of a monetary value to the carbon sequestered or on avoided emissions constitutes an effort to internalize an environmental externality in a monetized economy. However, using the carbon benefit yardstick leaves out other related externalities such as those represented by the criteria for sustainable forest management, while the host country and/or the international community may want to include them when evaluating the cost-effectiveness of climate-mitigation projects and policies.

Furthermore, mitigation project may create a new set of externalities which were non-existent prior to the project. For example, a new forest project may hinder seasonal migration of wildlife or introduce crop vermin (negative externality), while a forest rehabilitation project may increase proximal crop pollination (positive externality). Such leakages, which have a monetary value, can directly be included in the cost-benefit schedule of the project, but those which are non-market spillovers will need to be qualitatively monitored and evaluated, balanced against the GHG benefits of the mitigation project.

We therefore conclude that the task of monitoring and verifying climate mitigation policies and projects requires a comprehensive monitoring regime which will include the impacts of such policies/projects on the existing commitments covered under non-FCCC standing agreements or policies such as those governing sustainable forest management. The final assignment of credits and determination of cost-effectiveness may require some level of arbitration with other interested parties.

\section{Acknowledgments}

This paper benefited from constructive comments and suggestions from Drs. Michelle Pinard and Jayant Sathaye. The reviewers bear no responsibility for any errors in the manuscript.

\section{References}

Aplet, G.H.(cd.): 1993, Defining Sustainable Forestry. The Wilderness Socicty, Island Press, Washington D.C.

Brasnett N.V.: 1953, Planned Management of Forests. Gcorge Allen Unwin Ltd, London. pp 118-119. 
Brown, S., Sathayc, J., Cannell M. and Kauppi, P.: 1996, Management of Forests for Mitigation of Greenhouse Gas Emissions. Working Group II, 1995 Sccond Asscssment Report, Chapter 24, Cambridge University Press, pp. 772-797.

Damodaran, A.: 1992, The Economics of Forest Conservation and Sustainable Development. In Proceedings from Seminar on Socio-economic Research in Forestry. Thrissur, India. 388-408.

D'Silva, E. and Apannah, S.: 1993, Forestry Management for Sustainable Development. An EDI Seminar Report. No. 32. The World Bank, Washington D.C.

Dixon, J.A. and Falcon, L.A.: 1989, The Concept of Sustainability: Origins, Extensions, and Uscfulness for Policy. In Society and Natural Resources, Vol 2, pp 73-84.

Fcarnside, P.M.: 1996, Amazonia and Global Warming: Annual Balance of Greenhouse Gas Emissions from Land-use Change in Brazil's Amazon Region. Paper Presented at the American Gcophysical Union Chapman Conference on Biomass Buming and Global Changc, 13-17 March 1995, Williamsburg, Virginia.

Food and Agricultural Organization (FAO): 1993a, Forest Resources Assessment 1990: Tropical Countries. Forestry Paper No 112. Rome.

Food and Agricultural Organization (FAO): 1993b, The Challenge of Sustainable Forest Management: What Future for the World's Forests? Rome.

Food and Agricultural Organization (FAO): 1995, Expcrt Mecting on Harmonization of Criteria and Indicators for Sustainable Forest Management. Background Note 2/95. (Unpublished).

Forest Harvesting Bulletin.: Summer 1994.

Freczailah, B.C.Y.: 1994, Sustainability and Tropical Forests. Tropical Forest Update, Vol. 4 No. 2.

Gane, M.: 1968, Martin Faustmann and the Evolution of Discounted Cash Flow: Two Articles from the Original German of 1849; translated by W. Linnard, edited with an introduction by $M$. Gane. Oxford University, Commonwealth Forestry Institute.

Goodland, R., Asibcy, E., Post, J., and Dyson, M.: 1990. Tropical Moist Forest Management : The Urgency of Transition to Sustainability. Environmental Conservation, 17:303-318.

Grace, J., Llyoid, J., McIntyre, J., Miranda, A., Meir, P., Miranda, H., Nobre, C., Moncrieff, J., Massheder, J., Malhi, Y., Wright, I., and Gash, J.: 1995, Carbon Dioxide Uptake by an Undisturbed Tropical Rain Forest in Southwest Amazonia, 1992 to 1993. Science 270: 778-780.

Intergovernmental Panel on Climate Change (IPCCa): 1995, Climate Change. Impacts, Adaptations and Mitigation of Climate Change: Scientific-Technical Analyses. Contribution of Working Group II to the Sccond Asscssment Report of the IPCC. Eds Watson, R.T., Zinyowera, M.C., and Moss, R.H. Cambridge University Press.

Intergovernmental Pancl on Climate Change (IPCCb): 1995, The Science of Climate Change. Contribution of Working Group I to the Second Assessment Report of the IPCC. Eds Houghton, J., Filho G., Callander, B., Harris, N., Kattenberg A. and Maskell, K. Cambridge University Prcss.

Intergovernmental Seminar on Criteria and Indicators for Sustainable Forest Management (ISCI): 1996, Background Document to the Seminar held in Helsinki, August 19-22, 1996.

International Tropical Timber Agrcement (ITTA): 1983, United Nation Conference on Trade and Development. Geneva, 1983.

International Tropical Timber Agrecment (ITTA): 1994, United Nations Conference on Trade and Development. Geneva, 1994.

Intermational Tropical Timber Organization (ITTO): 1990, ITTO Guidelines for the Sustainable Management of Natural Tropical Forcsts. ITTO Technical Series 5. ITTO, Yokohama, Japan.

International Tropical Timber Organization (TTO): 1992, Critcria for the Mcasurcment of Sustainable Tropical Forest Management. ITTO Policy Development Series 3. Yokohama, Japan.

Johnson, N. and Cabarle B.: 1993, Surviving the Cut: Natural Forest Management in the Humid Tropics. WRI. Washington, D.C.

Lanly, J.P.: 1982, Tropical Forest Resources. FAO Forestry Paper 30. UN Food and Agricultural Organization, Romc, Italy.

Lugo, A. and Brown, S.: 1992, Tropical Forests as Sinks of Atmospheric Carbon. Forest Ecology and Management 48: 69-88.

Maini, J.S.: 1993, Sustainable Devclopment of Forests: A Systcmatic Approach to Defining Criteria, Guidclines, and Indicators. In: Procecdings of the Seminar of Experts on Sustainable Development of Borcal and Temperate Forcsts: Technical Report - Annex I. Conference on Sccurity and Coopcration in Europc, pp. 61-70. 
Maser, Chris.: 1994. Sustainable Forestry: Philosophy, Science, and Economics. St. Lucie Press, Florida.

Makundi, W., Sathayc, J. and Mascra, O.: 1992, Carbon Emissions and Sequestration in Forcsts: Case Studies From Scven Developing Countries. Vol. 1: Summary. LBL Report No. 32119.

McRac, M:: 1997, Is Good Wood Bad for Forests? Comment in: Science Vol. 275: 1868-1869.

Michacl, A.: 1992, The Difficulty in Defining Sustainability. Resources for the Future, No 106.

Mycrs, N.: 1984, The Primary Source: Tropical Forests and our Futurc. W.W. Norton and Company, New York.

Noordwijk Declaration on Atmospheric Pollution and Climate Change.: 1988, Ministerial Conference on Atmospheric Pollution and Climate Change, Noordwijk.

O'Riordan, T.: 1988, The Politics of Sustainability. In Sustainable Environmental Management: Principle and Practice, ed. R. K. Turner. London: Belhaven Press, Boulder: Westview Press.

Peters, C. M., Gentry, A.H. and Mendelsohn, R.O.: 1989, "Valuation of an Amazonian Forest". Nature 339:655-56.

Pinard, M. and Putz, F.E.: 1997, Monitoring Carbon Sequestration Bencfits Associated with a Reduccd-Impact Logging Project in Malaysia. In: This Issue.

Poorc, D., Burgess, P., Palmer, J., Rietbergen, S. and Synnott, T.: 1989, No Timber Without Trees: Sustainability in the Tropical Forest. Earthscan Publications. London.

Prabhu, R: 1994, Assessing Critcria for Sustainablc Forestry. Presented at The International Conference on Forest Product Certification Systems held on Scpt. 1994 in Pacct-Puncak, Indoncsia

Qucsada Mateo, C.A.: 1990, 'Sintcsis de ECODES,' in Estratcgía de Conscrvación para el Desarrollo Sostcnible de Costa Rica, MIRENEM, San Josć, Rcpublic of Costa Rica, p. 310.

Solomon A.M. and Cramer W.P.: 1993, Biospheric Implications of Global Environmental Change. In: Vegetation Dynamics and Global Change. [Solomon A.M. and H.H. Shugart (cds)]. Chapman and Hall, New York. pp 25-52.

United Nations.: 1992, UN Framework Convention on Climate Change. Ncw York, New York.

World Bank: 1992, A Strategy for Asian Forestry Development. Asia Technical Department. Washington D.C.

World Commission on Environment and Development: 1987, Our Common Future. Oxford: Oxford University Press.

World Resources Institute (WRI): 1987, Tropical Forestry Action Plan: Recent Developments. WRI. Washington D.C.

World Resources Institute (WRI): 1991, Summary Report on the Coloquium on Sustainability in Natural Tropical Forest Management. WRI. Washington. D.C. 


\title{
Sustainable Forest Management for Climate Change Mitigation: Monitoring and Verification of Greenhouse Gases
}

\author{
Edited by \\ Jayant Sathaye, Willy Makundi, and Beth Goldberg \\ Environmental Energy Technologies Division \\ Lawrence Berkeley National Laboratory \\ Kenneth Andrasko \\ Climate Policy and Programs Division \\ Office of Economy and Environment \\ Office of Policy, Planning, and Evaluation \\ U.S. Environmental Protection Agency \\ Arturo Sanchez \\ Research Center on Sustainable Development \\ University of Costa Rica
}

October 1997

Publication of these proceedings was funded by the U.S. Environmental Protection Agency, Climate Policy and Programs Division, Office of Economy and Environment, Office of Policy, Planning, and Evaluation through the U.S. Department of Energy under Contract No. DE-AC03-76SF00098. 